\title{
XX
}

\section{Rapid Prototyping for Social Science Research}

\author{
Carey Jewitt, Kerstin Leder Mackley, Douglas Atkinson and Sara Price
}

\section{INTRODUCTION}

Given social science researchers' increasing interest in materiality and embodied practices, there is considerable potential for productive methodological engagement with design-based research practices. In this chapter, we explore the potential of conducting social science research 'through design' (Lupton, 2018:2, emphasis added). We reflect on a series of workshops investigating the societal implications and impact of digital technologies on the mediation of touch communication. The workshops used the design-based research method of rapid prototyping as a quick and approximate way to engage with ideas of remote digital touch communication that draw the body, touch and materiality into focus. Our emphasis in this chapter is on illustrating the kinds of insights that can be gained through this method, rather than an exhaustive analysis of touch.

The chapter first introduces our rationale for using prototyping and our methodology. The second section illustrates the potentials of rapid prototyping as a socially orientated methodological strategy that enabled us, as qualitative researchers, to attend to the body as a meaning making resource, and to materialize ideas, sensory knowing, and wider discourses of personal remote digital touch communication. Drawing on selected episodes from the workshops, we show how this method helped participants to describe, explore or discover 
aspects of touch communication or stimulate dialogue. This enabled us to ask methodology and content focused questions including: What could we learn about touch through touch during the process of making? How did participants use touch as a form of telling and imagining? What were the social meanings and tensions that emerged around touch and the digital? How were experiential categories employed and made meaningful by participants in the process of making? In the final section of the chapter we reflect on the strengths and limitations of rapid prototyping for social science research, and suggest future developments for its use within social sciences.

\section{BACKGROUND AND METHOD}

\section{Researching remote digital touch communication}

Exploring the social implications of digital touch technologies is complex as it is an emergent, and to some extent imagined, communicative space. The complexity of researching digital futures raises methodological challenges. We cannot observe emergent technologies in everyday use, yet waiting for technologies to be commercialized and 'domesticated' misses critical opportunities for reflection. Exploring digital futures around touch requires methods that engage with bodies and sensorial experiences. Rapid prototyping explicitly draws the body into ways of knowing, exploring, thinking and being. It can both support and prompt touch and tactile experiences, through participants' bodily interaction with materials and one another, and helps to generate social insights and imaginations of personal remote digital touch communication.

\section{A brief introduction to prototyping}

Prototype, from the Greek Protos (first) and Typos (mold, pattern, impression), refers to a 'raw presentation of ideas' (Rudd et al., 1996: 76). Prototypes are practice and object-orientated, 
and can range from a sketch to a virtual or physical model at different stages of development - from what a design object 'looks like', 'behaves like', to 'works like' (Buchenau and Suri, 2000:424): and in the case of our research, what it 'feels like'. As a method, prototyping has its origins in product development within Engineering, Design, Computer Science, and Human Computer Interaction. Typically, it has been concerned with developing 'an idea about a product, system, service or policy to meet human needs and devising a plan for executing that idea' (Binder et al., 2011). Rapid prototyping emerged, in the 1990s as an approximate way to engage with ideas using basic materials and tools, and became associated with Design Thinking, 'a human-centered design process to problem solving, change or ideageneration' (Lupton, 2018:3). It advocates for 'thinking with your hands' as a way of quickly and practically exploring an idea and the feasibility and development solutions to pre-empt wasting time and money on something that might not work or might not be 'user' centred (Dunne and Raby, 2013) in a quick, cost-effective and contextually aware way. The reorientation of prototyping to high level concepts and ideas, rather than design products and skills, has enabled it to travel across the boundaries of engineering and design into the humanities and social sciences, including anthropology (Salazar et al., 2017), and sociology (Lupton, 2018), although less so in the latter and with different emphasis and foci.

As social researchers with an interest in the multimodal and multisensorial qualities of touch, the ways prototyping enables the body to play a central role in generating qualitative data are significant. We saw in rapid prototyping the opportunity to allow participants to externalize unrefined concepts in material ways and, in the process, identify and clarify key aspects of their ideas. As a method which affords 'a degree of ambiguity that fosters the design process instead of blocking it' (Innella and Rodgers, 2017: S1155), prototypes can be reflected on, assessed, and refined, and provide a prop for participants to enact the experience of using proposed artefacts. It also enables people with no prior design experience to share 
and explore concepts through the process of making, touching, and manipulating materials and objects together. As such, its processes are useful in promoting collaborative thinking and gaining new knowledge about relevant phenomena (Camburn et al., 2017).

\section{Rapid prototyping for social research}

The methodological migration of prototyping to social research has partly been fueled by a desire to research 'emerging and uncertain worlds' (Myers and Dumit, 2011; Salazar et al., 2017), notably imagined digital futures, 'configuring future imaginaries that may not be expected to come to pass' (Lupton, 2018:5). This aligns well with researching the unstable, uncertain, future-facing technological devices and environments associated with digital touch. Our use of rapid prototyping places this study within a wider move to innovative and creative social science methods (Jewitt, Xambo and Price, 2017). This movement has spawned a number of 'creative' 3D research methods that similarly take into account embodied meaning-making practices.

Lego Serious Play has been developed as a creative process in which participants learn to build representations of their ideas or experiences in Lego. It is seen as a way to share ideas, collaborate, and reflect on their experiences or working practices, thinking and building metaphors in relation to individual identity and experiences. The method offers a quick and easy way for participants to 'assemble a range of meanings' (Gauntlett, 2015: 5). Creative methods are frequently used in focus groups; for example, participants may be asked to construct plasticine models of their identities to solidify the abstract issue of identity, and thus talk openly and in-depth about such issues (Abrahams and Ingram, 2013). Another example is 'Sandboxing', a projective technique that allows 'the expression of thoughts and feelings on a symbolic level' (Mannay, Staples and Edwards, 2017: 347). Adapted from the psychoanalytical approach of the 'world technique', it involves participants creating three- 
dimensional scenes in sand-trays, employing miniature figures and everyday objects as a form of qualitative social inquiry. The emphasis of these methods is actively 'constructing a 'world' that can provide visual and verbal metaphors that enhance individuals' selfunderstanding' (Mannay, Staples and Edwards, 2017: 348).

The choice of materials is a key difference relevant for our study of touch. While rapid prototyping supports a wider range of materials, associations, and embodied experiences - including the making of cheap large-scale prototypes that can be sat in, worn and so on - Lego is a commercially manufactured construction toy consisting of interlocking plastic building blocks with strictly built-in, fixed affordances. Plasticine modelling and Sandboxing are similarly limited, particularly in relation to the embodied interactions they afford. In addition, these materials are associated with play and childhood which brings with it a set of limitations. Another key difference is that rapid prototyping is primarily a collaborative group design process to iterate ideas through making, while the focus in these other methods is on the individual - identity-narration and self-reflections, and mainly restricted to 'assembling'.

\section{Researching through the body}

Connecting rapid prototyping with a social science frame provides a route to otherwise difficult to articulate bodily experiences, imaginations, and knowledge (Tarr, GonzalezPolledo, and Cornish, 2017: 1). We argue for the need to work with and beyond the visual to account for the multimodal and multisensorial qualities, experiences and feedback of tactile and embodied processes of meaning-making. Chadwick (2016:54), however, has noted that, 'While social science interest in embodiment is old news and researchers have been attempting to 'bring the body back in' (Frank, 1990) for the last 30 years, there is still little work which has reflected on the methodological aspects of the 'turn to bodies'. Chadwick's 
concern is that most methodological strategies that attend to the body continue to be inadequate as they are 'fundamentally based upon talk about the body and bodily experience' (2016: 57).

This chapter takes up the challenge of researching through the body. Within science and technology studies (STS). Myers and Dumit's study of lab researchers argues through the use of detailed ethnographic work, that attending to the 'affective sensibilities' acquired by researchers at work in their labs shows 'bodies as excitable tissues for gathering up the energetics and movements of the world, and manifesting these as perception, affect, and action' (2011:239). Puig de la Bella Casa, explores touch through a feminist and STS perspective to argue that 'Attention to what it means to touch and to be touched can increase awareness of the embodied character of perception, affect and thinking' (2009: 297). Critical reflection on the methodological aspects of the turn to bodies is also central to recent work within Feminist New Materialism and Posthuman methodologies, which argue that the use of arts-based methods 'can summon new forms of voicing, thinking, feeling and being to emerge' (Renold, 2017:40).

Understanding bodily knowing through research on and with the body is a founding feature of the authors' work within multimodality (Jewitt, Bezemer and O'Halloran, 2016; Jewitt, 2014; Kress et al., 2001, 2004) and sensory ethnography (Leder Mackley and Pink, 2014). Our analysis of participants' rapid prototyping combines a multimodal and multisensorial lens to explore how participants know and tell through touch and bodily interaction. We set out to understand when and how bodily modes (gesture, gaze, movement, posture, position and touch), the sensorial and materiality are brought into the scope/discursive space of making and demonstrating prototypes, as a way to generate understanding of participants' conceptualizations and realizations of digitally mediated touch. 


\section{Workshop method}

The data presented in this chapter is from three research workshops designed to move beyond the notion of the constructed object as a prompt for talk (using the making process to generate talk), interaction (types of touch and other bodily actions) and imaginations on remote personal communication and remote 'touch' communication. The workshops focused on remote personal communication and consisted of a sequence of five activities across a three-hour period.

1) Brainstorming through small group discussion

2) A sensory tour

3) Rapid prototyping

4) Reflective and sensory engagement with a remote-communication prototype

5) Quick-fire discussions of concepts related to remote digital touch communication.

The workshops were designed and led by four project researchers. The sensory tour and rapid prototyping sections were facilitated by two expert 'maker-facilitators' from UCL's Institute of Making and the Royal College of Art, who assisted participants in practical aspects of prototyping processes. This enabled the IN-TOUCH team to focus on workshop activities as part of the wider research encounter.

Workshop participants were recruited via four London-based postgraduate programs and research networks. Attendance was voluntary and refreshments were provided. The first workshop recruited university staff (professional and academic) from an interdisciplinary research center on technology and learning. Participants for the second and third workshops were postgraduate students studying Media and Communication, Design, Computer Science, and Linguistics. We targeted these participant groups since they were trained in different 
disciplinary perspectives and likely to have different interests in the digital and processes of communication.

A total of 31 people participated in the workshops: workshop 1 (10); workshop 2 (13); and workshop 3 (8). Participants were selected on the basis of availability and achieving a disciplinary mix of attendees. Participants were originally from Japan, China, Germany, Finland, Sweden, Italy, Brazil, America, UK, Switzerland, and Turkey; they ranged in age from 22 to 51 years old; 25 were female and six were male. This enabled the groups to draw on a range of linguistic and cultural experiences. In line with Innella and Rogers (2017), the focus of prototyping on creative doing and making appeared to reduce linguistic barriers to participation and brought forth communicational differences in productive and discursively useful ways.

\section{Workshop activities}

We focus on insights from activities 1 to 3 in this chapter, each of which are outlined below. To provide an initial context for the workshop, participants worked in small mixed disciplinary groups (3-4 people) for 15 minutes, brainstorming their histories and experiences with different types of distance communication technologies. Prompt questions were: Where does remote communication happen, and who with? What technologies do you use? How has your experience of remote communication changed over the last 10 years? What sensory experiences does remote communication enable? Participants used post-it notes to record their discussion. Feedback from the activity generated a mapping of the groups' experiences of remote digital communication and explored cross cutting themes.

During the sensory tours an expert 'maker-facilitator' introduced and guided participants around a 'buffet style' array of available materials, displayed on a large table at the center of the workshop room. The sensory tour was akin to 'tactile window-shopping' to 
give felt experiences and spark ideas and participants were encouraged to physically engage with materials. These included foam/polystyrene shapes, cardboard and paper sheets, fabrics (fun fur, felt, silk, leather), plastic and glass containers, rubber and silicone, pipe cleaners, feathers, plasticine, play-dough and air clay. An A to Z list of touch words (written on post-it notes) from 'bite' to 'yank' was displayed alongside the materials, which participants were invited to read, take, and add to, to support ideation around touch-based practices, this sparked conversations, clarifications and translations. Tools available included hot glue guns, scissors and cutters, markers, tape, Velcro-fasteners, and they were selected as they do not require any particular skill in order to enable participants to produce models. Participants brought different experiences, skills, and understandings of materials, tools and processes of making to the workshop and different social, cultural and scientific capital were in play. Each group was given a large basket to 'shop' for materials throughout the prototyping process. The touch words and sensory tour were designed to serve as a bridge between the brainstorming around remote digital communication and the prototyping process focusing on touch-based communication.

The aim of the rapid prototyping session was introduced by the IN-TOUCH team, and an expert 'maker-facilitators' gave a short introduction to the process of prototyping. All participants were given a card which set out its aims and key elements. While developing their concept or artefact, participants were encouraged to consider who would use it, how each material may translate into a function/experience, and the parts of the body they wanted to engage. We chose material-based, object prototyping over 2D prototyping as it has been shown to encourage a high level of bodily interaction and potentially draw a higher level of engagement from participants (Deininger et al., 2017). Participants were given 40 minutes for the sensory tour and prototyping process. This was followed by 10 minute prototype demonstrations from each group, combined with an opportunity to ask and respond to 
possible questions.

\section{Data collection}

The use of video was central to the workshops, not only as a record of activities to be analyzed in retrospect, but also as a reflective tool for the generation of data across our combined theoretical-methodological frameworks of multimodality and sensory ethnography (Jewitt, Leder Mackley and Price, 2018). We used video cameras to record the activity of each small group, supplemented by researcher observations throughout the duration of the workshop. Fixed cameras were used to record the interaction of participant groups at each of the tables, and hand-held (iPad) cameras were used to capture participant interactions with the materials away from the table. We moved and occasionally 'felt' with participants, in an effort to gain insights into their experiences. The video data was supplemented by iPhone audio recordings of each table. We maintained a balance between listening to, probing and prompting the groups regarding the overall workshop aim, activities and time schedule.

The data generated through the workshops include over three hours of video (and audio) recordings for each group, a collection of photographs, text-based data (post it notes, flip chart notes, our research field-notes, participant evaluations), and a set of 10 prototypes produced by the participants. For this chapter, the video recordings are our primary data source as our analytical focus is on prototyping as process, although we do draw the prototypes and other data sources into the analysis.

\section{Our analytical approach}

Our approach draws on both multimodal (Jewitt, Bezemer and O'Halloran, 2016) and sensory ethnographic (Pink, 2015) approaches (see Jewitt, Leder Mackley and Price, 2018 for a full discussion of this combined lens). Working within this lens the video analysis focused 
on generating a fine-grained account of participants' multimodal and multi-sensorial interactions and experiences with one another, materials, and the prototypes, with attention to a range of bodily modes - position, posture, gesture, gaze, and movement alongside speech and on how these relate. This analytical frame is particularly suited to this context where making and doing are central.

An inductive data driven approach was used to develop analytical themes. Our engagement with the workshop videos began through re-viewing the recordings as a team, making notes of interactional details, reflecting on our own embodied experiences of the workshops and materials, and revisiting and handling participants' prototypes with attention to their sensorial and social properties. We then focused on the prototyping process, paying specific attention to how materials were brought into the making, through which parts of the body, in relation to the research questions noted earlier. The analytical process of immersion and iterative engagement with the video involved generating descriptive notes and the conceptual development of themes, followed by focused attention to repeated actions, revelatory moments, and how events unfolded in/over time towards exploring significant practices and norms. Through this process the video materials were assembled to explore, develop and refine analytical themes relevant to digital touch communication. We then explored our themes across the video recordings. This involved allocating segments of data to the themes and building a collection of data around them. Three themes are discussed in this chapter: materiality, mapping the body, and negotiating the interface. We interrogated these themes by viewing video of the prototyping process, enacting the prototypes, and working with different researchers' analytical views of these.

We present an analysis of episodes from three prototypes (one from each workshop), the making of which exemplified three themes that emerged as central to understanding digital touch and the wider workshop activities socially, communicatively, experientially and 
methodologically (Table 1). These themes and related episodes are not exhaustive but selected to illustrate the potentials of rapid prototyping as a socially orientated methodological strategy.

\begin{tabular}{|l|l|l|l|}
\hline Prototype & Materials & Interface & $\begin{array}{l}\text { Location on } \\
\text { body }\end{array}$ \\
\hline Haptic Chair & $\begin{array}{l}\text { Chair } \\
\text { Fake fur } \\
\text { Balloon } \\
\text { Tissue paper } \\
\text { Bubble wrap } \\
\text { Cotton fabric } \\
\text { Yogurt pots } \\
\text { Playdoh } \\
\text { Silicon } \\
\text { Tape }\end{array}$ & $\begin{array}{l}\text { Whole body } \\
\text { Morpher }\end{array}$ & $\begin{array}{l}\text { Polystyrene } \\
\text { balls } \\
\text { Air clay } \\
\text { Pipe cleaner } \\
\text { Cocktail sticks } \\
\text { Glitter } \\
\text { Glue } \\
\text { Cotton filler }\end{array}$ \\
\hline
\end{tabular}




\begin{tabular}{|l|l|l|l|}
\hline $\begin{array}{l}\text { Hugging- } \\
\text { Cape }\end{array}$ & Fun fur & Air-clay \\
Cotton fabric & Felt
\end{tabular}

Table 1. Three workshop prototypes

\section{RAPID PROTOTYPING AS A SOCIALLY ORIENTATED}

\section{METHODOLOGICAL STRATEGY}

\section{Materiality}

The sensorial engagement with a range of prototyping materials and the opportunities these would create for touch-sensitive thinking, exploration and ideation were central to our workshop design and an emerging theme. Our selections of resources aimed for variety and versatility in terms of materials and their sensory qualities. Our interest was as much in what we could learn about digital touch from participants' provisional materializations as it was in how the very act of rapid prototyping and participants' sensorial engagements with materials interrelated with (rather than determined) their sensing, imagining and speculating. In some moments, participant ideas emerged from general conversations, and participants chose materials to best represent them. In others, participants' sensory encounters with materials were central to bringing forth processes of ideation and imagination.

Some materials seemed to evoke very particular associations. Fur repeatedly brought forth stroking and petting touches, and memories of participants' pets. This became central to 
a prototype in one group whose device allowed a member to remotely join their partner (on another continent) during dog walks. In other cases, the 'pet' was part of a wider environment, as with the design of the 'haptic chair' that evoked the feeling of sitting on someone's lap, and the calm stroking of an animated cat sleeping on the arm rest. The haptic chair prototyping illustrated to us the fluidity of the ideation process in relation to the materials. Prior to engaging with available materials, the group had spent some time working out what kind of experience they wanted to create, drawing on their sensory-embodied memories of touch, talking and acting out postures, and discussing the kinds of existing remote touch technologies they were already aware of (for example the Cute Circuit HugShirt). They began with the idea of hugging which involved them in lots of bodily demonstrations of self-hugging, toward creating a 'machine that can hug you or nudge you that isn't really obvious technology'. They imagined this to be a chair, or a set of connected chairs that would enable people to hug each other at a distance. When bodily enacting the experience of a hugging chair, possibly with arms embracing the user from the back, they acted out how an embrace could soon become scary, being held back by the chair. This led to the idea of sensing someone's presence through heat and soft pressure, without holding on. Then thinking of sitting on someone's lap, specifically a grandparent's lap but maybe a partner's.

Encouraged to start building the device they began to 'augment' a chair, initially with different layers of fabric and bubble wrap, the former representing touch sensors, the latter inspiring the idea of sensing others through the inflation or expansion of materials. Engaging with the sensory materials further opened up the experience of the haptic chair from the initial concrete ideas of hugging and sitting on someone's lap to the creation of a multisensorial environment that had at its core both the connection with others and the notion of relaxation. As group member, D, commented, 'it's expanding from just the idea of a hug to 
pretty much every touch possible'. What became the 'virtual' or haptic cat on the arm rest was part of creating that calming sensory environment, as was the later addition of speakers represented by yoghurt pots (see also interface section below). A specific moment when materials seemed to evoke an element of the design that hadn't previously been envisaged was when R's attention was drawn to a not yet inflated balloon. She stretched it between her hands in a rehearsed motion, inflated it and placed it underneath the fur on the armrest, giving the haptic cat shape at the same time as representing a material that would rise and fall with the cat's animated breath [ $R$ used rising and falling hand movements to illustrate this] commenting 'it's funny, it actually feels like a cat.' The engagement with the balloon is an example of how participants improvised with known material properties in a way that would attach new affordances and possibilities to the materials, as well as adding a sense of authenticity.

Whereas the fur brought with it specific tactile associations and types of touch, other materials gained significance through their malleability and ambiguity, leading the 'hugging cape' group to propose more intuitive forms of user interfaces and the idea of new languages of digital touch (see interfaces). As participants in the 'tactile emotion morpher' group handled the air-clay, their touch was tentative while naming its 'weird' and slightly 'unsettling' tactile-sensory properties. Initially reluctant to touch it, they explored the clay through its packaging, then opened it up, pressed and stretched it with their thumbs, experiencing and discussing its moistness. The touching, stretching, shaping and pulling apart of the clay was indicative of participants' thinking through their hands and they agreed it could be used to represent the emotion of disgust. They were testing materials for their tactile properties and creating tactile sensations to explore their emotional meanings; cotton, something that needed to be caressed, came to represent 'sadness'; and a green Playdoh ball 
was fitted with wooden spikes, pressing and poking, so as to represent anger (with pain and anger closely aligned; Y: 'cos when I'm in pain, I get angry').

The serendipitous and improvisatory nature of thinking through their hands was evident in how the group came to create the central building block of their tactile emotion morpher, a process which was led (though not straightforwardly determined) by the coming together of different materials.

Having agreed that they wanted to create something that involved a range of positive and negative sensory and emotional experiences, $\mathrm{G}$ picked up a small polystyrene ball, twisting it initially in her right hand, then rolling it between both hands as though she was creating a dough ball.

Y: 'You can kind of feel someone's tension, so if you're having a conversation that's pretty like intense, you kind of get a...'

G: [starts squeezing the polystyrene ball with her right hand] 'Like a stress ball...' [passes the 'stress ball' to B who continues the squeezing action with her right hand]; Y: 'Yeah, or maybe "I'm pushing my limits here, like, with this", or...'

$\mathrm{G}$ then picked a coffee cup holder and a yoghurt pot, arranging them upside down on the table, experimentally stacking the objects and the 'stress ball', feeling it between her fingers. As it rolled off the cup holder, she caught it, briefly letting it roll away on the table, then placing it back on the cup holder, before B picked it up again. At this point, $G$ took another polystyrene shape, a larger ball with two indents at opposite sides, and placed it on top of the cup holder. The shape of the indented ball immediately prompted B to place the smaller polystyrene ball into the indentation, commenting on its neat fit with an 'ooh' of recognition, 
gently manipulating the small ball with her finger tips ' This could be like a joystick'. Y joined her, reached out to the polystyrene ball to mimic B's scrolling actions (Figure 1).
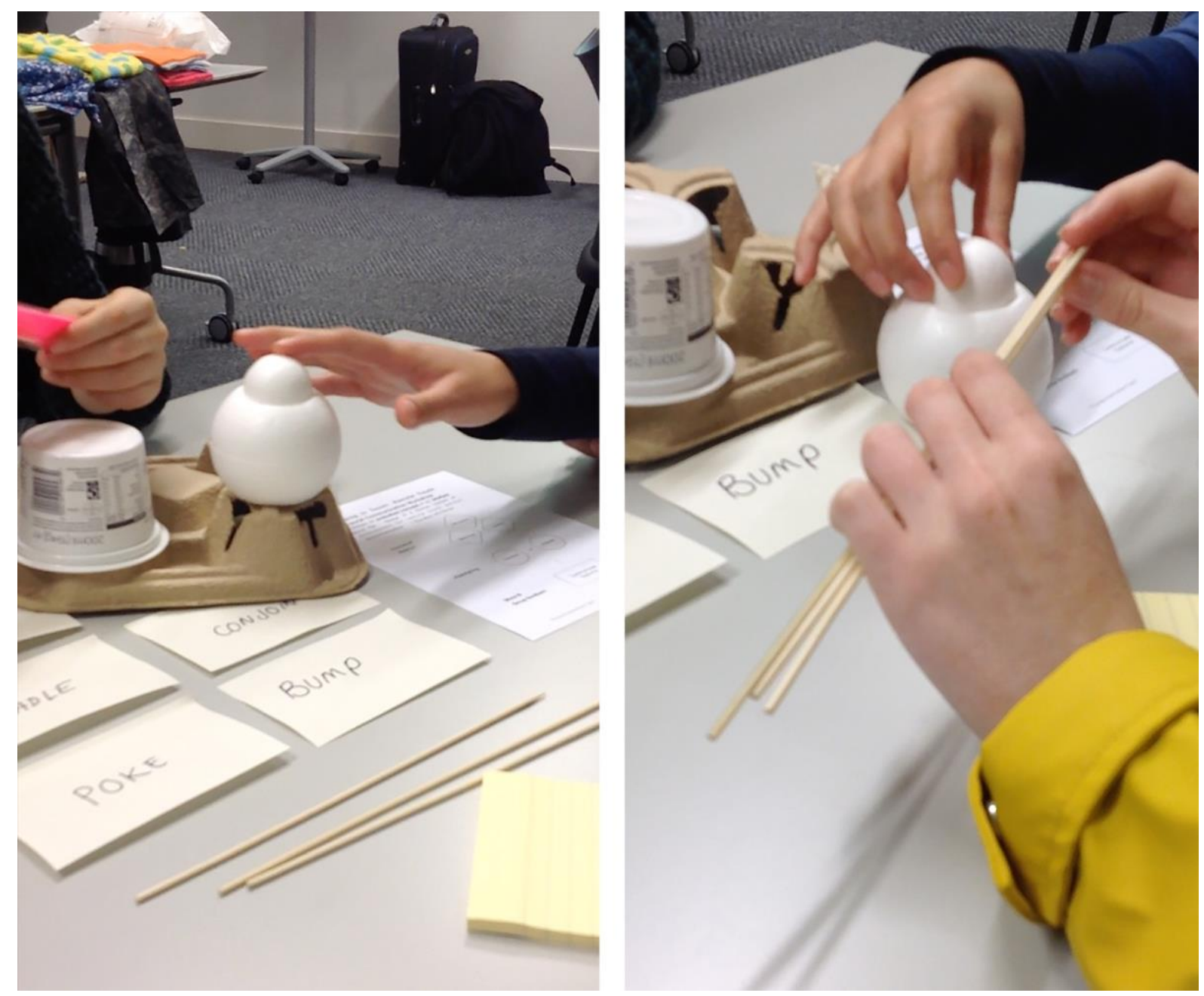

Figure 1: The 'tactile emotion morpher' group thinking with their hands

As the group touched, scrolled, pointed, rolled, rotated the ball in different directions, gestured back and forth movements, and 'hit' the ball, they reminisced about online gaming and different game controllers. Reconciling this idea with their earlier touching and sensorial experiences of the materials, $\mathrm{G}$ suggested that a console could work to display different tactile representations of emotions. B picked up the small polystyrene ball again, noting that it could become 'something like a circle.., a sphere of emotion.' Y's actions and comment 
that it seems like a mouse (or the scrolling ball/wheel on top of a computer mouse) prompted B to imagine and interact with it as a control wheel that would display a spectrum of emotions, or their intensities. Their tactile interaction with the polystyrene ball and their imagining of it as initially part of a control device and then of a more dynamic visual-tactile emotion display illustrates playful negotiation between known and speculative technologies and interfaces.

\section{Mapping touch and technology to the body}

Hands were central to how participants explored, manipulated and transformed materials in the process of making, but throughout the workshops all participants used their bodies in the prototyping sessions as a resource for thinking and experimenting through and with. Mapping their exploration of digital touch experiences to the body was central to this process, either by their recounting of memories of touch, mimicking or actual touching of objects and materials, self-touch or by touching others in the group.

The 'hugging cape' group wrapped, draped, and stretched materials on their bodies and demonstrated using self-touching to support their exploration of types of touch tensions and sensations. They gesturally 'pantomimed' types of touch with an imagined person or object, pretending to poke a person, or trying out different hand shapes for touch. Gendered and religious social touch norms were visible and felt in the group (as in all of the groups) making different touch resources available to the male and female participants. Social norms of distance and personal touch, articulated via the social context of being in London and at a workshop, were visible (and doubtless felt) in the way the three women ( $\mathrm{S}$-from London, $\mathrm{N}$ Germany, and L-Brazil) touched each other over the course of the workshop. After some initial tentative touching (accompanied by laughter), they began touching more frequently 
(without laughter), to hug one another, and eventually to fully embrace. They frequently echoed each other's touch practices (see Figure 2). They also explored a hugging touch by embracing one another, used their hands and bodies in these ways to explore and help articulate the physical sensation of a hug, and to break it down into identifiable physical constituent parts, that map to ideas of pressure, scale, warmth, and duration (Figure 2). They linked these physical aspects with the social: 'touch to show warmth and affection'. The process of making led them to conceptualize a hug as a 'transferring of touch', which raised questions of the bodily location of a hug and the sensations of hugging (as well as the interface - the need for two connected devices - discussed in the next section). The man (D) in the group noted that as an Italian he would usually touch a lot, but in the group context he touched others less than the women. He demonstrated a prototype on the forearm of the white European woman in the group - for which he asked permission, but otherwise did not touch, hug or embrace other group members: he observed social norms. 


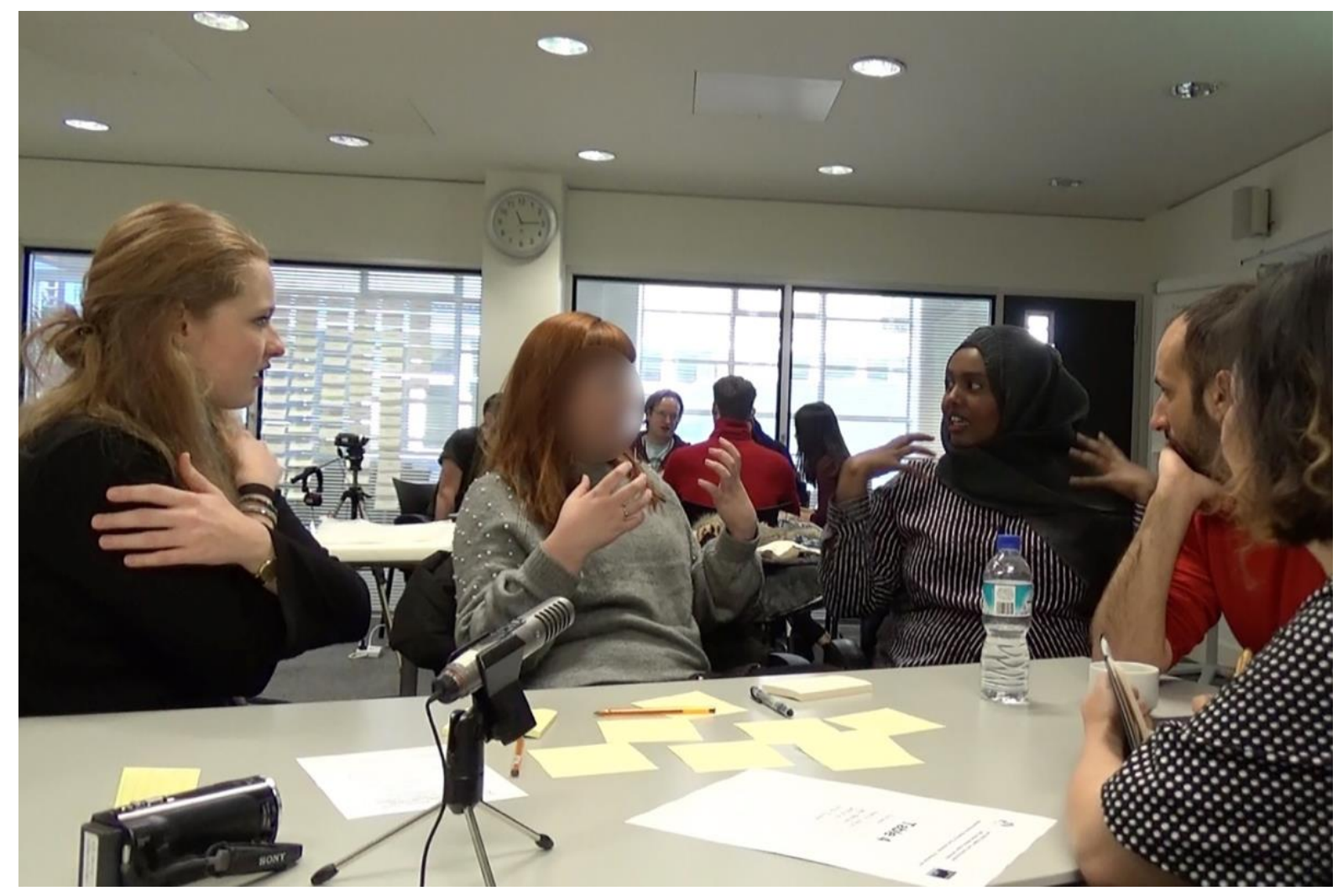

Figure 2: The 'hugging cape' group thinking with their hands and bodies

$\mathrm{N}$ : But where... when you hug someone...[she mimes hugging someone in front of her, she puts her arms out, embraces the imagined body, she moves her arms up and down, outwards and inwards, the others in the group watch] Where do you feel the pressure? Where is the hug?

The group started to work with how their device might map to the body as a 'site' as a bodily response to N's question, 'where is the hug?'. They located the materials they had selected on different parts of their (and others') arms, around the neck, the shoulders, across the whole torso, and like a blanket across the knees. These bodily actions, and further engagement with the materials - rolling of the air-clay in their hands, stretching and 'warming it', draping the cloth on their body - led to experiences of temperature and feel which then entered their understanding of the experience they wanted to create. 
Through wrapping their bodies participants developed the idea of being enveloped as a sensation and settled on a wearable device. Their bodily experiences of being wrapped and draped, evoked memories and discussions that led to the idea of scale and flexibility as important features. This led to more focused draping and wearing experiences, and the idea of a large scarf or a blanket, which could be folded or extended to give different touch experiences. Through the process of engaging with the materials on their own and eachothers' bodies, the group returned to the problem of where the hug will 'be' and how the sender of a remote digital hug will know where they are touching.

$\mathrm{N}$ : [wrapping the material around her body, she hugs herself] As the person hugs self, its transferred to another person? Are the input and the output the same? [she is trying to reach her arm to hug her back]

S: We are trying to build freedom into the experience

$\mathrm{N}$ : Wraps the cloth on her arm

L: It is not just transference it is an exchange - we both feel and we both can...

S: That's how I was thinking...

$\mathrm{N}$ : But the problem is that we said a hug is anywhere here [trying to touch her back] so it's difficult for me giving a hug like this to her

S: Give yourself a hug like that [crosses her arms in front of her chest]

$\mathrm{N}$ : Copies $S$ 's gesture and smiles she appears happy with the symbolic solution L: But it depends where you put the blanket

The location of touch was key to their understanding of what kind of touch is being sent, bringing the idea of authenticity and accurate mapping to the body into play. That is, they linked the fidelity of the sender's intent to the location of the touch. The physical realization 
of the potential for social ambiguity in relation to the meaning of touch led to the 'flexibility' of touch location being removed from the prototype design.

The 'haptic chair' group also drew on self-touch, touching materials, imagined touch experiences and touch memories in their prototyping process to map the body to a digital 'device'. Participants re-articulated, materialised and elaborated these themes through the embodied process of making. They worked to map digital touch to a range of body parts, sensory capacities (temperature and hearing), and postural ergonomics. Through this process they came to agree that someone touching you is a 'soft' experience, more about heat than movement, with pressure, but not too much. The idea of 'someone being there', of being gently held (contained). To create an ephemeral sense of 'being present' the chair's design combined heat pads (orange circles of tissue paper laid across the lines of the legs and the base of the 'cat') to give a sense of warmth, and pressure sensors (pink foam pads). The group's augmentation of the chair thus brought a tactile interface into view that would utilise and communicate to the whole body a sense of pleasure, reassurance, calmness and intimacy.

\section{Touch technology interfaces}

The task of developing a prototype device, system or environment inevitably involved the groups with the concept of touch technology interfaces. They drew on their past and current experiences of interfaces to imagine their extension into the realm of touch; used their knowledge and experience of current touch-interfaces as a starting point for exploring or reimagining touch; or actively tried to move away from and beyond known interfaces and technologies. Each of these types of engagement were supported by material and bodily exploration of potential interfaces. There was a coherence with, and integration of, features of old, contemporary and novel technological interfaces - although the introduction of touch appeared to raise new concerns. The ability to send, to record (and store) touch experiences 
were consistently circulating as useful and concerning aspects of an interface for personal remote digital touch. While the participants recalled their experiences with contemporary communication technologies (for example, mobile phone apps such as Whats App, Snapchat, texting, email, Skype/FaceTime), there was also much connection with 'older' interfaces and communication contexts (for example, being fixed to the spot by landlines, and answer phones). We suggest that this is connected to the nostalgia of the past (Ruppel, 2009) and, differently so, participants' associations of touch with childhood. However, participants expressed a desire to break with these experiences and connections.

This tension is illustrated in the interaction between participants in the 'hugging cape' group. They worked with a recognizable object - a blanket or scarf, and a known touch experience - a hug, exploring how to translate that into a digital experience. The three women use the idea 'input and output' to explore the touch experience of a hug - hugging themselves, watching their hugging, and hugging one another. Their exploration prompts the fourth member (D, the man in the group) to propose an alternative, less direct and more malleable, touch interaction system:

D: I'm thinking about kinds of interactions I would have with this [mimes touching and pulling a scarf or blanket around his neck] how I could interact with it? The thing is, we have very malleable things [gestures malleable changing fluid] but we lack this malleability [gestures at the interface design of the cape]... So, I'm wondering if we can do something with a material that doesn't explicitly have a clear interaction? So the clay - imagine you have a phone like that [holds arm out with clenched fist as if holding a shape], and you call people by [squeezes fist] squeezing it, or when you do this instead [pulls arms apart as if stretching the clay] then it will send a message. $[D$ 
picks up a mobile phone case and imagines that it is made of a kind of malleable material, and 'scratches' it] Like with a phone case made of this kind of material you have a case you might send a scratch, or heat via the phone case. With this kind of device, you don't have any instructions - you have to work out how to use it. So, it's up to you to associate a particular meaning with an action - so it's very personal right'

Participant $\mathrm{D}$ is trying to move the prototype away from the idea of the digital as a direct translation of a human analog interaction experience, in this case a hug, and to move away from standardized interface design and the 'normalization' of 'template interfaces'. He has a different vision for digital touch that supports new touch capacities, practices, experiences and communicational forms. However, his idea is incorporated by the other participants into the 'hugging cape' prototype in relation to the transfer of heat as a form of touch-based connection and interface, as the participants $\mathrm{L}$ and $\mathrm{N}$ each harness the improvisation of using their hands to explore the idea of temperature and touch communication via a phone case:

L: [Holds her phone in her hand, flipping it over] I want to make my family in Brazil feel what I feel.

$\mathrm{N}$ : [starts to handle her phone]

L and N: [holding and handling, turning over, their phones in their hands] S and D: [watch at L and N's hands]

L: Today in London it was one degree: I want to make my family in Brazil feel what I am feeling [she takes the phone in her hand and taps it] 'TAP'! 
The group continues to explore D's notion of an ambiguous interface, and the idea of sending and receiving touch. D suggested they do 'an experiment', an enactment, he uses his hands to roll out three small balls of air clay. Setting out the three balls in a row, he proposes that one of them plays the sender - the input, another plays the receiver - the output, and the third (D) 'plays the technology'. He wanted the sender to 'deform' the clay - make an impression on it, the technology to 'copy' and send the shape and the receiver to 'interpret' it. The idea is for them to hold, mold, and make shapes with the clay as a way of interacting 'like a personal language of touch'. This suggests there are different understandings (even theories) of communication in the group, differences that require different types of interfaces. The prototyping process of $\mathrm{N}, \mathrm{L}$ and $\mathrm{S}$ approaches communication as transmission or direct transfer, and digital touch as mimicking analogue face to face touch experiences. In contrast D approaches communication as an interactional meaning making process and digital touch as having a potential to enable the emergence of personal vernacular 'languages' of touch. D's intervention did not re-orientate the hugging cape prototype and the tension between these positions emerged, as did the gendered polarization of touch experience in the group:

D: So I on the other side will have the same blanket?

$\mathrm{L}$ and $\mathrm{N}$ : [hug each other, holding the 'hug position' to try and understand where they will need to put the 'pressure and heat sensors' on the cape]

D: 'But she is a human! If we are trying to re-enact a hug from a machine - it's sad, it's super sad. All we are doing, basically, is we are trying to associate something very warm and human with a motor pushing on your shoulder S: That's the whole point of remote communication [to reproduce what's missing] 
Given the acknowledged bonding effect of touch we can speculate whether the gendering of touch may have shaped the group dynamic in ways that were significant for the prototyping process. D was trying to get something different into the interaction, to move digital touch beyond a mechanical abstraction, or distilling of specific locations for pressure to convey the idea of a hug. They discussed how it can be 'creepy' and 'uncanny' to try and reproduce human touch in machine form. The final prototype cape included the air-clay as a material-a layer beneath the fabric so that the interface would support different types of touch experiences that utilize both the idea of directness and ambiguity in different ways. Ambiguity and directness thus became qualities of digital touch communication, which could be used to develop a user based 'bespoke language of touch'. This enabled the prototype to move away, albeit slightly, from a communicational model of one-to-one direct transmission to incorporate the idea of open interpretation by users. Ambiguity was seen as having a potential to lead to interesting possibilities of developing a language of touch - a form of touch personalization.

As an interface the 'haptic chair' group also utilized the body to generate an 'unorchestrated immediacy' with the ease of a casual meeting rather than an arranged time and set up which becomes 'performance and too staged' or 'practiced'. The interface was a response to their desire to ameliorate the social impact of speed and convenience on personal communication at a distance (for example, calling in transitional spaces and gaps in schedules when on the move). Specifically, they wanted communicators to be able to have a sensory imagination of the location and activities of the person they were communicating with: a sensory response to the ubiquitous 'mobile' questions, 'where are you?', and 'what are you doing?'. The group had an abstract shared imagination of a personal remote digital touch communication experience, which evolved into the haptic chair interface as they engaged with the materials and environment available: 
D: How would it work? What sort of materials? How to make a machine that can hug and touch but isn't obvious technology [They are standing and there is a chair in front of them]

R: [Touching the back of the chair] Could it be on a chair? Could it be a chair? ...

E: How would you make it properly feel like a hug? Like someone touching you.

R: [Holds the chair, and starts to gesture possible actions of the chair]

The other prototypes made in the workshops had automatic, ever-ready, intuitive and nonintrusive interfaces. While the 'haptic chair' was initially envisioned as an 'invisible' interface, buttons repeatedly surfaced in their making process. In the final prototype buttons emerged as a visible way of indicating on and off, send, measure heart-rate, record (body messages), replay, interpretation (relaxedness level) and to block interaction:

R: [picks up on the 'nudge' post-it note] Maybe you could have a nudge then, maybe you could have an extra vibration when someone else sits in their chair [the corresponding chair] to let you know they are there in case you want to interact with them, and you can decide whether you accept it or not [points at a silicone 'button'] ?

For this moment, the haptic chair interface linked to their ideas and experiences of a phone or camera - existing communicative devices. Nonetheless, through the process of making, the group also moved toward the idea of 'closing distance' through an interface that was quiet, intuitive, 'natural' and 'invisible' (so as not to be remarked on) via a whole body sensory interface. This produced the idea of a 'body message', that is, the sending of tactile messages, in which you record taps, movements, the shape of the body and its impression - via pressure 
and heat, that can then be played and felt. In this way, the haptic chair became a multisensorial environment that affirmed the importance of place, sound, and visual (imaginations) for touch-based experiences. The group later considered a portable version, in which the layered chair interface could be 'rolled up and taken anywhere'.

Returning to the 'tactile emotion morpher' group, the small polystyrene ball had initially sparked tactile interaction akin to working with a joystick or computer mouse. Entertaining this idea, B rolled the ball in different directions and suggested that it could work like an emotion wheel, moving from neutral into different stages of anger and back. The four sections of the cup holder led to some quick internet searches about four basic emotions (anger, happiness, sadness, fear - with surprise and disgust as additional emotions) inspiring a concept of communicating and, thus, tangibly displaying emotion states on the cup holder, with the polystyrene base as a control station (Figure 3). The group agreed that this would enhance communication partly because emotions cannot always be read across distance, and partly because some cultural differences or learning difficulties may hamper communicating or reading emotions per se. The group's changing focus towards how to represent emotion through touch (for example, through associating painful touch with anger) invited B to reflect on the kind of control or lack thereof the interface should entail: 'It's hard to say how I'm feeling, it's like who wants to take the time to say how they're feeling - maybe that way... this would indicate maybe what the other person's feeling - that's how I feel, and then you touch it [mimics touching Y's wooden spikes, quickly pulls back her hand], ow, that's how you feel?!'. 

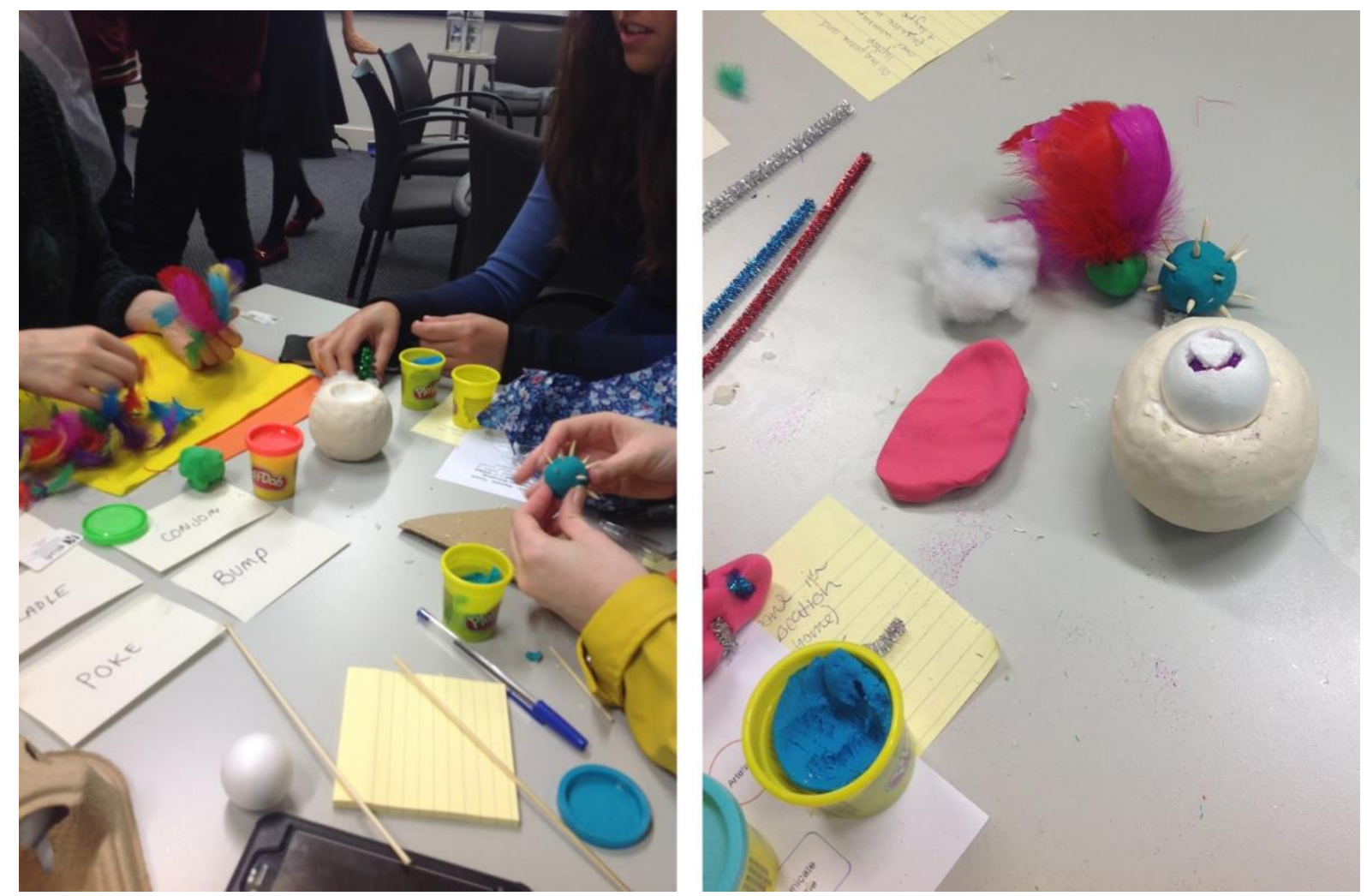

Figure 3: The tactile emotion morpher prototyping process, and the finished physical emotion representations: from left to right - disgust, sadness, happiness, anger, surprise

This notion that the system should read people's emotion and automatically (involuntarily) communicate it through its tactile display led the group to reconsider its interface as something that was mobile, soft and fluid: 'something like a hologram'. They imagined a system that would respond to facial expressions ('micro expressions') to read people's emotions, rather than one that would detect emotion through touch. The final prototype became a material representation of what they considered a more fluid, morphing object in its ultimate form, one that could also resemble more ambiguous emotion states. As such, they worked with 'a technology [and an interface] that doesn't exist yet' but appears to be rooted in haptic VR. 


\section{METHODOLOGICAL REFLECTIONS}

\section{Strengths/opportunities of this approach}

This paper builds on and contributes to the use of visual and modelling methods within social science to provide access to experiences and research data that is otherwise out of reach. Specifically, we have illustrated the potential of rapid prototyping within a social science frame to provide social insights on the 'hard to access' and future facing experience of digital touch communication: here with attention to three themes that emerged across the workshops, materiality, mapping touch and technology to the body, and touch technology interfaces.

A significant methodological aspect of the rapid prototyping workshops is that they brought bodily and materially orientated forms of exploration, discovery and experiencing of touch communication to the fore. This emphasis gave participants multimodal and multisensorial opportunities to use their bodies as an investigative means in the research workshop, engaging with remote personal digital touch communication in ways that differ than those provided by a talk-based or 2D visual-based focus group. The experience of prototyping can create new collaborative contexts that evoke and provoke a new awareness and criticality of touch and can support participants to explore their experiences, memories and imaginations of touch, their touch practices and skills, and engagement with the features and character of touch as a communicative form. The process helped participants to externalize and materialize their ideas: literally to put them on their body and feel them, to provide tactile experiences and explorations.

This, when combined with our analytical approach enabled us to bring the multimodal, sensorial and experiential aspects of touch to the forefront of the participant experiences. The prototype ideas emerged through participant engagement with a range of materials, the act of making, their own bodies and the bodies of others in the group. A process that enabled problems to become apparent and be resolved, and that enabled 
participants' collaborative thinking to be further refined and consolidated through the process of making and demonstrating their prototypes. This approach brings attention to bodily interactions and situates language within a complex multimodal and multisensorial environment, in which language is but one part of a complex of overlaying and interrelated senses and modes.

Our lenses orientated to touch, the body, the sensorial and material offer a distinct analytical approach to prototyping as both process and artefact. A key difference in our approach to prototyping, as compared to design concerns, is our interest in and analysis of making as a process through which to get at what people think about touch - rather than the design of touch, per se. One of the potentials of design within social science noted by Lupton (2018:7) is to provide a productive way for sociologists to orient their research to contribute to the informed development of new technologies and systems.

\section{Limitations of this approach}

The approach in this particular study has several limitations that raise more general considerations when using the method. The perceived democratizing capabilities of creative and inventive methods raises the question of who they can be used with, who might be excluded, and the appropriateness of using them with specific participant groups. While the physicality of rapid prototyping needs to be considered in relation to the abilities of participant groups it has been used productively with people living with a range of disabilities, including visual impairment (Giles, van der Linden and Petre, 2018). The participants for our study came from a range of international contexts and varied in their levels of English proficiency - whilst this could disadvantage some participants in expressing their ideas in a talk-based research context, rapid prototyping led to many clarifying conversations that did not appear to exclude them from the making process or contributing to 
the exploration of digital touch communication. The experience, knowledge and capacities of the participants also needs to be considered. Our participants (postgraduate students and university staff) could largely be described as members of a global educational elite: with a high level of social and cultural capital, specialist knowledge and training. While not all participants had encountered rapid prototyping before, and none had engaged with digital touch or its communication as a topic, some had (varying) experiences with making or prototyping and the digital, contact with theories of communication, and knowledge of digital communication research. However, rapid prototyping is not a specialist driven research method. It can, and has, been used with a wide range of participants including people from local communities in the context of health and well-being, disability, and employment.

A consideration and potential limitation when using embodied and physically based methods is how to reflexively engage with the social-cultural norms that diffract research participant experiences. While these norms are always present and often in play in significant ways, a focus on touch interaction brought to the fore, made visible and felt, the norms of touch and gender as they intersect with culture and religion in ways that appeared to shape the groups' interactions. The framing, location and process of rapid prototyping, along with the materials made available and the expertise needed to facilitate the processes also shapes the methodological focus. For example, we chose to use everyday materials and (primarily) everyday tools rather than specialist computing or design materials to enable all participants to engage in the process of making and thinking through the body, rather than a polished artefact, whilst acknowledging that those from a design or computing background would likely be more adept at making.

As with any method, it is important to understand the limitations of the claims that can be made using the data generated through rapid prototyping workshops. In addition to the methodological questions addressed in this chapter, this data enables us to talk about 
exploratory themes, ideas, and imaginations that circulate among the participants: How did participants use touch as a form of telling and imagining? What were the social meanings and tensions that emerged around touch and the digital? How were experiential categories employed and made meaningful by participants in the process of making? In short, this method cannot be used to make generalized claims about remote personal touch communication. Findings from these exploratory rapid prototyping workshops could however, be used to inform the development of an actual digital touch communication design, or as a starting point for developing further research on digital touch communication.

\section{Considerations and questions}

Below we provide some key questions that may be helpful to consider when using rapid prototyping as a method in the context of social science research.

Research purpose: How might rapid prototyping help me address the research questions at the heart of this study? How will attention to the embodied multimodal and multisensorial process of making help me to address or generate relevant research questions?

How am I using Rapid Prototyping: Rapid prototyping can be used along a continuum from a relatively open or closed form of exploration. On the one end, it can be used to make tangible a familiar idea, or to test or adapt existing devices (for example, take an existing touch technology and adapt it for a specific type of user); at the other, it can be used as a projective technique that engages the participant in something entirely novel. It is important to ask ourselves: where is my study is on this continuum?

Participants: What capacities, knowledge and skills of my participants do I need to account for in the design of the rapid prototyping session (for example, their physical dexterity or strength in tool use, their sensory acuity in relation to materials)? Do they have experience of 
practices of making? What social and ethical issues might the study focus raise and how will these be dealt with in the organization of the session or the groupings?

Materials: What type of materials do I want to provide to participants: an expansive range or a restricted selection? Everyday or specialist, natural or synthetic, what domains will the materials be associated with? What colours, textures, shapes, sizes or scales of materials will be provided (for example, small items or large packing boxes that a person can sit in?).

Tools: What tools will be provided: everyday and/or specialist; what skills will participants need to use these?

Set up: How will the workshop materials and tools be organized (categorized) or displayed? Would an introduction to the materials, for example a Sensory Tour, be helpful for participants to familiarize themselves with the materials? Will participants be allowed to select from a wide range of materials or will a set of materials be allocated to each group? Facilitation: What making skills or experiences does the research team have? Will expert facilitators with specific rapid prototyping skills be present to support the participants to make?

Framing: What scenario or questions will be used to frame the rapid prototyping activity? Activities: What activities would help the participants to 'get into' that frame: for example, brainstorming, role play, discussion or question cards? This may be particularly important in the context of social science research where participants may not be familiar with, wary of or even afraid of, making something.

Stages of prototyping: Prototyping is an iterative process of thinking through making including initial ideation (discussion, sketching, interacting with materials), ideation through making, discussion, iteration, presentation. Will the process be organized into discreet phases or stages? 
Timing: How long do participants need for each stage of the prototyping? This is a balanceon the one hand, it is important to give participants a feasible amount of time to make something, on the other hand it is important to help participants (especially the wary ones) avoid over-thinking or over-planning by not allowing too much time.

Documentation: What needs to be documented for the study? The prototypes, the process of making or both? Even if the prototype can be kept for research purposes the documentation matters as they are often not robust and their materiality changes as they age. How will the prototype be documented - as an object 'enlivened in use', as a disembodied object? They may not always make sense when not in use. How will this be achieved - audio recording, video recordings, photographs, post-it notes, observation notes? If video, will the camera be static or roaming (following participants), will wide angle or close-up video recording be used?

Working with the data: We have illustrated the application of a multimodal and multisensorial analysis. Two key questions for us were: how to enter into the data via the multimodal and the multisensorial rather than through talk, and how to sample the data for episodes to analyze in depth?

\section{Future developments}

The multimodal data generated through the workshops discussed in this chapter have several potentials for future development. This chapter has focused on the embodied process of prototyping, rather than the prototypes that were produced. However, the prototypes also lend themselves to analysis. In the context of our project, for example, we will conduct a multimodal and multisensorial analysis of them, to explore their semiotic resources, affordances, and materiality (Jewitt, Bezemer and O'Halloran, 2016) in relation to social discourses of digital touch interaction that circulate through these artefacts. Such an analysis 
would lend itself to a discussion of participant imaginations of digital touch devices and environments. We have made a case that rapid prototyping is particularly useful in generating socially orientated understanding of future experiences or imaginations. The workshop data, the prototypes and the video recordings, could be used to generate further analytical trajectories via speculative scenarios (Dunne and Raby, 2013) in the form of fictional narratives that incorporate or respond to debates about touch within the news or research literature. Such scenarios could serve as analytical vignettes, or provide a starting point for further elaboration within a follow-on workshop (with participants who made the prototypes and/or with researchers working within touch communication) to further investigate conceptions of digital touch communication or to inform digital touch interaction design.

\section{ACKNOWLEDGEMENTS}

With thanks to the workshop participants, and to Caroline Yan Zheng and Romain Meunier for facilitating the rapid prototyping workshop session. This work was undertaken as a part of the IN-TOUCH project, a European Research Council Consolidator Award (Award Number: 681489).

\section{REFERENCES}

Abrahams, Jessica and Ingram, Nicola (2013) 'The chameleon habitus: Exploring local students' negotiations of multiple fields', Sociological Research Online, 18(4) 21 http://www.socresonline.org.uk/18/4/21

Binder, Thomas, De Michelis, Giorgio, Ehn Pelle, Jacucci, Giulio, Linde, Per, Wagner, Ina. (2011) Design Things. Cambridge, MA: The MIT Press 
Buchenau, Marion and Fulton Suri, Jane. (2000) Experience prototyping. In Proceedings of the 3rd conference on Designing interactive systems: processes, practices, methods, and techniques

Camburn, Bradley, Viswanathan, Vimal, Linsey, Julie, Anderson, David, Jensen, Daniel, Crawford, Richard, and Wood, Kristen Lee (2017) Design prototyping methods: State of the art in strategies, techniques, and guidelines. Design Science, 3. doi:10.1017/dsj.2017.10 Chadwick, Rachelle (2016) 'Embodied methodologies: challenges, reflections and strategies', Qualitative Research, 17(1): 54-74.

Dunne, Anthony and Raby, Fiona (2013). Speculative Everything: Design, Fiction, and Social Dreaming. Cambridge, MA: The MIT Press.

Gauntlett, David (2015) Making Media Studies: The Creativity Turn in Media and Communications Studies. New York: Peter Lang.

Giles, Emille. van der Linden, Janet. and Petre, Marian. (2018) Weaving Lighthouses and Stitching Stories: Blind and Visually Impaired People Designing E-textiles. In: Proceedings of the 2018 CHI Conference on Human Factors in Computing Systems.

Giovanni Innella and Paul A. Rodgers (2017) 'Making sense: Harnessing communication through prototyping', The Design Journal, 20:sup1, S1154-S1166, DOI:

$10.1080 / 14606925.2017 .1353058$

Rudd, James, Stern, Kenneth, and Isensee, Scott. (1996) 'Low vs. high-fidelity prototyping debate', Interactions, 3(1): 76-85.

Jewitt, Carey, Xambo, Anna and Price, Sara (2017) 'Exploring methodological innovation in the social sciences: the body in digital environments and the arts', International Journal of Social Research Methodology: 20(1): 105-120.

Jewitt, Carey, Bezemer, Jeff and O’Halloran, Kay (2016) Introducing Multimodality. London: Routledge. 
Jewitt, Carey (2014) Handbook of Multimodal Analysis. London: Routledge.

Jewitt, Carey, Leder Mackley, Kerstin and Price, Sara (in press 2018) 'Methodological

dialogues across multimodality and sensory ethnography: Digital touch communication',

Qualitative Research.

Kress, Gunther, Jewitt, Carey and Ogborn, JON (2014) Multimodal Teaching and Learning.

London: Continuum/Bloomsbury.

Kress, Gunther, Jewitt, Carey, Bourne, Jill, Franks, Anton, Hardcastle, John, and Jones, Ken. (2005) Urban English Classrooms: Multimodal Perspectives. London: Routledge.

Leder Mackley, Kerstin and Pink, Sarah (2014) 'Framing and educating attention: a sensory apprenticeship in the context of domestic energy research' in Lydia Arantes and Elsa Rieger (eds). Ethnographien der Sinne: Wahrnehmung und Methode in empirisch-

kulturwissenschaftlichen Forschungen, Bielefeld: transcript, 93-109.

Lupton, Deborah. (2018) 'Towards design sociology', Sociology Compass, 12:e12546. https://doi.org/10.1111/soc4.12546

Mannay, Dawn, Staples, Eleanor and Edwards, Victoria (2017) 'Visual methodologies, sand and psychoanalysis: employing creative participatory techniques to explore the educational experiences of mature students and children in care', Visual Studies, 32(4): 345-358.

Myers, Natasha. and Dumit, Joe. (2011) 'Haptics: Haptic creativity and mid-embodiments of experimental life', in F. Mascia- Lees (ed.), A Companion to the Anthropology of the Body and Embodiment. London: Blackwell. pp.240-261.

Pink Sarah (2015) Doing Sensory Ethnography. London: Routledge Pink, Sarah (2014) 'Digital-visual-sensory design anthropology: Ethnography, imagination and intervention, Forum: Ethnography and Design', Arts \& Humanities in Higher Education, 13(4): 412-427. 
Puig de la Bella Casa, Maria. (2009) 'Touching technologies, touching visions. The reclaiming of sensorial experience and the politics of speculative thinking', Subjectivity 28: pp. 297-315.

Renold, Emma (2017) '“Feel what I feel': making da(r)ta with teen girls for creative activisms on how sexual violence matters', Journal of Gender Studies, 27(1): pp. 37-55.

Ruppel, Marc. (2009) 'You are then, this is now: nostalgia, technology and consumer identity at CES 2007', Social Identities, 15(4): 537-555.

Salazar, Juan Francesco, Pink, Sarah., Irving, Andrew and Sjoberg, Johannes. (eds.) (2017) Anthropologies and Futures: Researching Emerging and Uncertain World. London:

Bloomsbury Academic.

Tarr, Jen. Gonzalez-Polledo, Elena. Cornish, Flora. (2017) 'On liveness: Using arts R workshops as a research method, Qualitative Research, Online first DOI:

$10.1177 / 1468794117694219$ 